\title{
ASO Visual Abstract: Iterative Cytoreduction and Hyperthermic Intraperitoneal Chemotherapy for Recurrent Mucinous Adenocarcinoma of the Appendix
}

Felipe Lopez-Ramirez, MD $₫$, Vadim Gushchin, MD, FACS $₫$, Michelle Sittig, RN $₫$, Mary Caitlin King, BS $₫$,

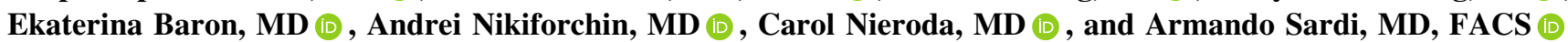

Mercy Medical Center, Department of Surgical Oncology, The Institute for Cancer Care, Baltimore, MD

Patients with recurrent mucinous peritoneal carcinomatosis from low- or high-grade appendiceal tumors showed a potential for prolonged survival when iterative cytoreductive surgery (CRS) plus hyperthermic intraperitoneal chemotherapy (HIPEC) is feasible. These procedures were not associated with higher complication rates than for the first CRS/HIPEC (https://doi.org/10.1245/ s10434-021-11233-1).

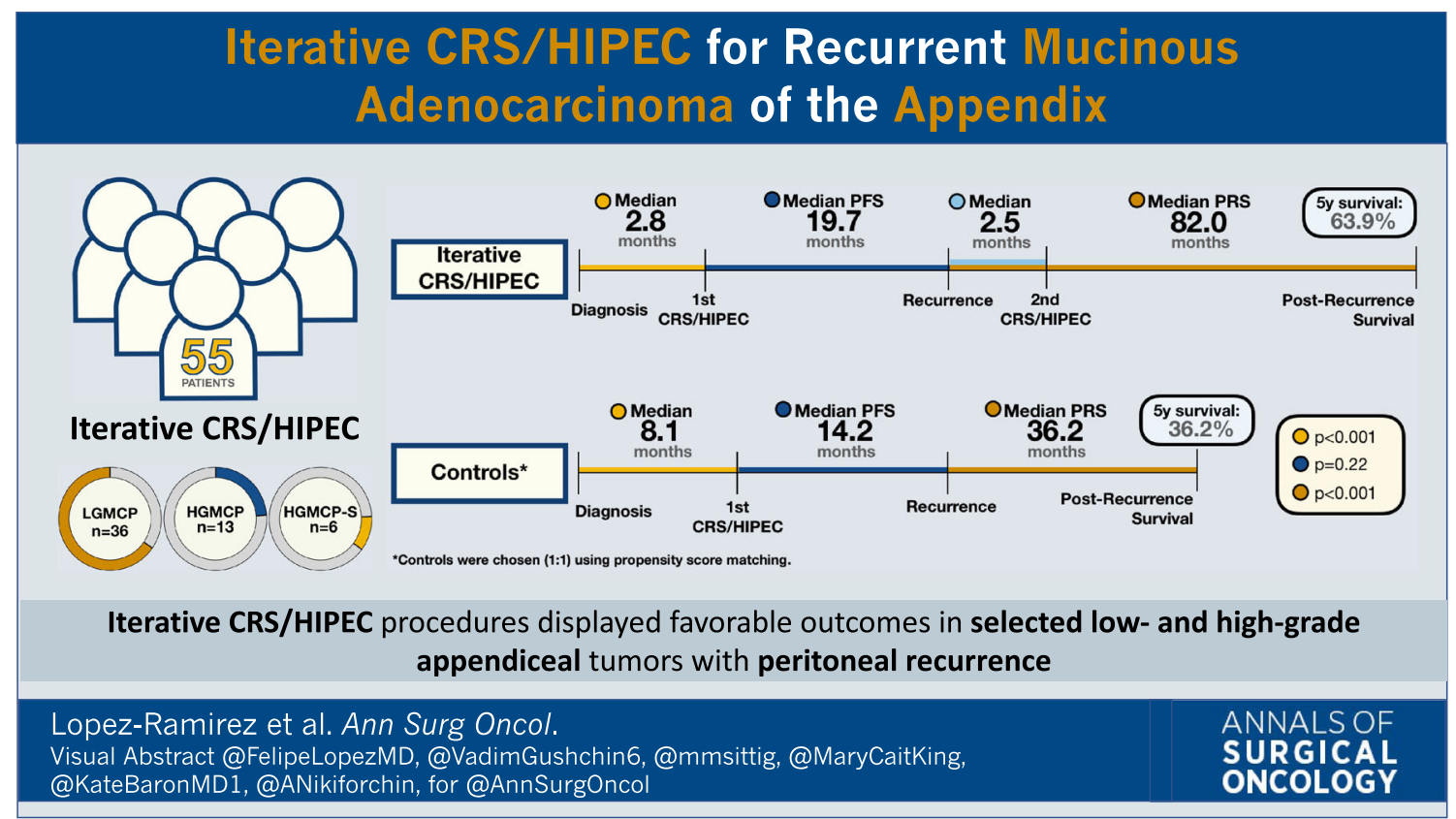

(C) Society of Surgical Oncology 2022

DISCLOSURE The authors declare that they have no conflicts of interest.

A. Sardi, MD, FACS

e-mail: asardi@mdmercy.com

Publisher's Note Springer Nature remains neutral with regard to jurisdictional claims in published maps and institutional affiliations. 